\title{
The role of Design as a barrier to and enabler of the Circular Economy
}

\author{
Dr Deborah Andrews, \\ Associate Professor, Design \\ School of Engineering \\ London South Bank University \\ 103 Borough Road \\ London SE1 OAA
}

\begin{abstract}
The development of a Circular Economy (CE) for products is being encouraged to reduce waste and conserve resources. Development is currently limited however and some research discovered that business and policy makers see the main barriers are cultural and market-based and lack of legislation rather than technological / design based. 'Design' is doing or planning something with a specific purpose in mind and therefore designed artefacts, services, systems and strategies can be transformative. In this chapter we discuss the role and importance of design as both a barrier to and an enabler of the Circular Economy and propose that design and technology are equally as important as social and financial factors. We consider the power of Design and its influence on Linear and Circular Economies in general and then with specific reference to three real world case studies; we also discuss the impact of different technologies on Circular practice and conclude that the Circular Economy is dependent on the integration of design, technology, social and economic criteria.
\end{abstract}

\section{$<$ a Introduction and Context}

The development of a Circular Economy (CE) for products is being encouraged to reduce waste and conserve resources. Development is currently limited and some research discovered that business and policy makers see the main barriers are cultural and market-based and lack of legislation rather than technological / design based (Kirchherr et al, 2018). 'Design' is doing or planning something with a specific purpose in mind (OUP, 2010) and therefore designed artefacts, services, systems and strategies can be transformative. In this chapter we discuss the role and importance of design as both a barrier to, and an enabler of, the Circular Economy and propose that design and technology are equally as important as social and financial factors. In this chapter we first consider the history of the design discipline and profession and its historical role in the Linear and Circular Economies in general, in order to appreciate its role as an enabler and barrier to the Circular Economy at present. We then consider three real world case studies to illustrate the impact of different technologies on Circular practice and ascertain the extent to which the Circular Economy is dependent on the integration of design, technology, social and economic criteria.

There is evidence that pre-human ancestors made stone tools-objects made for specific purposes -5 million years ago, and since then design has been practiced in conjunction with other occupations such as craft, engineering, architecture and construction. Although it is not possible to determine the precise date when design was recognised as an activity and profession in its own right, the discipline has evolved continually with and since the industrial revolution and industrialisation since the 1750s.

For example, developments in print technology necessitated new typography and accelerated the reproduction of images and communication materials, which initiated the graphic design discipline and profession from the early 1800 s. Textile and clothing production were similarly accelerated by the introduction of multi-spindle and steam-powered looms and the sewing machine in 1764 and the 1830 s respectively; paper patterns were also designed and circulated, which, with the couture 
resulted in the fashion design profession. Many other industries including transport, agriculture and product manufacture similarly evolved alongside machines; these also had to be designed, manufactured and maintained, as a result of which education and training programmes for industrial engineers were developed to facilitate production in a 'material age of rapid transition, from abstract, to applied science' (Armengaud, 1848).

At this time the design of many mass-produced household goods mimicked that of hand-made items; in the 1870s however, Christopher Dresser (a Scot and one of the first independent designers), sought to change this by developing a new simpler and more modern aesthetic that was better suited to industrial manufacturing processes. This shift represents the beginning of the discipline of industrial design (which has subsequently become synonymous with product design) of which Christopher Dresser is often cited as the father.

Industrialisation simultaneously depended on and contributed to developments in technology, increasing wealth, Gross Domestic Product (GDP) and expendable income. As GDP rose, global poverty decreased from 94\% in 1800 to 52\% in 1991 (Bourguignon \& Morrisson, 2002), which established and strengthened the consumer demand-supply-income cycle (Goossens et al, 2007). The increasing demand-supply-income cycle presented significant opportunities for designers and the discipline and the profession grew from the 1850s as they created desirable goods and services. These simultaneously made emerging technologies (e.g. telephony, automobiles, radio, electrical goods) acceptable and comprehensible to domestic users and expanded the market for capital goods, manufacturing equipment and energy in general. While industrial designers utilised and exploited new materials (such as polymers (plastics)), graphic designers utilised evolving communication technologies to increase and support the emerging marketing industry, all of which further contributed to mass-market consumerism.

Initially the market for novel products and services was self-sustaining and it was enough for designers to introduce consumers to new products that saved labour, provided continuous light and increased light levels for example. In 1929 however the Wall Street stock market crashed, and triggered a global economic recession as a result of which the manufacturing and design industries stagnated. The concept of 'planned obsolescence' was therefore introduced in 1932 (London, 1932) specifically to stimulate and revitalise the demand-supply-income cycle. Design was critical to this strategy and was employed as a physical and psychological tool to implement it. The way in which products were manufactured at the time meant that many could be repaired, which, along with reuse, extended product life; in the case of 'planned obsolesce' design was used to develop products with limited life to encourage replacement; one example was light bulbs, production of which was controlled by a Cartel who reduced bulb life from 2500 to 1000 hours. Design was also used to persuade consumers to purchase goods by creating "the desire to own something a little nicer and a little better, a little sooner than necessary" (Stevens in Adamson, 2005). This became the norm even though some designers disagreed with these strategies and individuals like Buckminster Fuller (who advocated 'doing more with less' materials and energy from late 1930s) and Victor Papanek (who lambasted his peers for 'wasting natural resources, aggravating environmental crises and ignoring their social and moral responsibilities' from the 1960s) were outside the mainstream (Andrews, 2015).

Although Buckminster Fuller and Papanek reacted against the negative aspects of design, they, like all other designers recognised the potential and power of design to solve problems, facilitate independence, empower people and improve quality of life as well as generate wealth. The British Government recognised these phenomena in 1944, when it established what became the UK Design Council to aid economic recovery. 


\section{$<b>$ Design and the development of the Linear Economy}

Early products either were designed to facilitate maintenance and repair or were simple to maintain and repair by default; at end-of-life, parts were also sold on, scavenged or decomposed because they were made from natural materials and this in conjunction with the relatively low volume of products in circulation meant that there was very little waste. While built-in obsolescence (i.e. takemake-use-and-dispose') stimulated the market, it also generated waste but this was not considered by designers and other professionals at a time when resources were deemed abundant and responsibility for products did not extend beyond the factory gate. The generation of waste was compounded by the widespread application of synthetic and non-organic and materials, which do not decompose. Increasing waste was also due to changes in manufacturing and assembly processes such as use of adhesives; composite and mixed materials also became common place as a result of which separation of parts became expensive, difficult and often impossible. Therefore, it is no surprise that unofficial and official landfill sites were developed to manage the ever-increasing volume of waste, and it is irrefutable that design has played a very significant role in the development of the Linear Economy.

\section{$<b>$ Circular Practices outside the Circular Economy}

The generation of waste is higher among affluent communities and during periods of abundance and prosperity than it is when resource costs are high or when expendable income is limited.

Consequently circular practices such as repair, reuse and recycling were and are commonplace when resources are limited and supply is erratic (e.g. prior to and during World War II and the economic boom of the 1950s and 1960s in the 'developed' world). Ad hoc reuse, repair and recycling are still widely practiced in the 'developing' world even though it is increasingly difficult to repair some products because of the way in which they are designed and manufactured. Although these practices contribute to a more sustainable economy they have decreased significantly in locations where they are either perceived as uneconomical, have been forgotten, are not taught or learnt, or are deemed unnecessary and undesirable as the emotional value of 'old' objects is often reduced when superseded by the new.

Since 1800 global population has risen from one billion to 7.7 billion, which has intensified demand on all resources including minerals, water, food and energy. These factors in conjunction with problems associated with the Linear Economy, and increasing demand on resources resulted in formalisation of the concept of the Circular Economy and its subsequent recognition by governments and some industries in the 2010s.

\section{$<b>$ Design and the Circular Economy}

Although design contributed to the Linear Economy, it also played and plays an important role in the development and promotion of the Circular Economy. For example, the ideas of the Swiss architect and economist Walter Stahel are fundamental to the Circular Economy: he has advocated use of waste as a resource since the 1970s, and in the 1980s he established the Product Life Institute, promoted product life extension and introduced the concept of Cradle-to-Cradle (rather than Linear Cradle-to-Grave) design (Stahel, 1981, Stahel \& Giarni, 1989). As encouraged indirectly by Victor Papanek, designer responsibility is also being formally acknowledged and all of which can help to reduce demand for virgin materials and energy use as well as waste.

The following guidelines are intended to overcome barriers to the Circular Economy and designers are encouraged to:

- design for maintenance, repair and upgrade to extend life

- design for disassembly to facilitate separation of parts for recycling and/or reuse;

- consider joining methods - ideally avoid adhesives and use mechanical and/or smart fixings

- minimise materials mixing unless performance is compromised when it should be limited 
- dematerialise - use less material without compromising performance

- use materials that can be recycled easily - consider alternatives to composites unless performance is compromised

(McDonaugh and Braungart, 2002; Ellen McArthur Foundation, 2013).

Some of the guidelines may conflict and it therefore essential to adopt a holistic approach to design for the Circular Economy and to balance all aspects of the design in relation each other. To date many products have been redesigned and reengineered in part to address specific problems but this often leads to different and further problems; this reinforces the need for a holistic approach to design for the Circular Economy and that design should be based on first principles (Transition Engineering, 2019), which also fosters genuine innovation.

\section{$<b>$ Summary}

Design has made innumerable positive contributions to social and economic development, improved quality of life, health and well-being and has benefitted billions of people and the environment since the industrial revolution. But it has also contributed to the development of a Linear Economy by applying a short-term cradle-to-grave ethos to the design of physical artefacts; this has in turn has influenced user behaviour and created a culture of disposability and associated negative environmental, social and economic impacts. The above design guidelines will facilitate development of the Circular Economy but implementation can be very challenging. History, culture, economics, geography, politics and user behaviour all influence the potential development of a Circular Economy. We now discuss the role of design as a barrier to and enabler of the Circular Economy and the inter-relationship between design and technology, social, and economic factors via two UKbased and one global real world case studies for three very different types of product.

\section{$<$ a $>$ Solar shading products - improved design will help CE in conjunction with behaviour change}

Solar shading products include internal and external blinds, shutters, awnings, louvre arrays, tensile structures and canopies. They have been used in many countries for hundreds of years and the fundamental concept of solar shading products has changed little although a number of patents relating to mechanism design have been published in Europe and the USA since the mid- $18^{\text {th }}$ century. Blinds and shutters etc. are passive energy saving products and research shows that they can reduce energy for heating in the winter months if closed during periods of darkness to reduce thermal loss. (Dolmans, 2006; Hutchens, 2015) They can also reduce thermal gain and one real-time study shows that in a specific London location during a summer 'heatwave' the operative temperature in a room with closed blinds was $9^{\circ} \mathrm{C}-13^{\circ} \mathrm{C}$ lower than a room without blinds (De Grussa et al, 2017). Blind use also improves visual and thermal comfort these products, which contributes to health and well-being of building occupants and increases productivity in the work place (De Grussa et al, 2018).

The global solar shading industry is very well established and in the UK alone annual sales are currently around $f 600$ million (AMA, 2018). UK manufacture started in the $18^{\text {th }}$ as a 'cottage industry' producing fixtures and fittings and consequently many construction industry professionals and customers continue to regard solar shading products as low value decorative furnishing items despite their various proven benefits. The sectoral business model has changed little, $73 \%$ of companies only employ 1-5 people, which in turn has influenced the design and manufacture of components, because they need to suitable for both hand and machine assembly and the majority push fit.

Window covering components are now made from traditional natural materials and from newer materials such as composites and polymers (which ensure that they do not deteriorate when 
exposed to sunlight for long periods). Similarly, almost all mechanism components are moulded polymers to facilitate functionality and assembly. The materials used for each of these components vary as they are selected for their inherent properties: for example, sliding parts are made from low friction materials (such as nylon or acetyl) and mechanism materials therefore mixed. Another change is operation and while many blinds remain manual, motorised and automated blinds are now readily available to domestic and commercial customers and sales of this type of blind are increasing, which increases the number and type of components. Product life can be as brief as 3 years and as long as 20 years depending on user preference and blind quality; assuming that blinds are used correctly the energy saving benefits of manual, motorised and automated blinds outweigh the embodied environmental impact of the products over life.

There are already some examples of Circular practice in the commercial solar shading sector where product life is extended through maintenance and replacement of damaged components. Some manufacturers also offer a fabric replacement service to domestic customers to enable them to update their blinds to fit new decorating schemes at the same time as encouraging brand loyalty; as yet buy in is limited. There is some recycling but rates are very low as it is driven by manufacturing waste legislation and occurs during production rather than by users at end-of-life. Although shading products can be disassembled and parts separated for reuse and recycling the majority of end-of-life products either end up in landfill or are crushed as part of the building demolition process and become hard-core. Disposal is due to the fact that many users do not know that the products can be disassembled. Even if there were manufacturer take-back schemes, the process can be timeconsuming which increases costs and there are no incentives to encourage take-back at present. As stated above solar shading products are regarded as low value, which also discourages circularity although this could change as sale of motorised and automated products and therefore actual cost increases.

It is apparent that the barriers to circularity in this sector are cultural, market and design-based and therefore changes in design and business models are needed to change behaviour and increase circularity. For example, better design for disassembly, fewer parts and/or materials mixing and disassembly instructions could encourage recycling rather than disposal. Substitute materials should also be explored to minimise mixing. When paired with incentives from businesses (for example discount for new products on receipt of disassembled and separated blind components) will develop brand loyalty and increase component reuse and recycling as long as businesses are rewarded rather than penalised for collecting materials for recycling. Manufacturers will be able to identify component materials, which will increase separation and improve the purity of recyclates.

\section{$<$ a $>$ Refrigerated Display Cabinets (RDCs)}

Refrigerated Display Cabinets are key to the cold chain, which ensures the hygienic and safe supply of fresh food 'from farm to fork'. Like solar shading products, the fundamental concept of RDCs has changed little since they were introduced in UK self-service retail food stores in the 1950s; since then production has increased concurrently with the self-service retail model and there are now more than 800,000 RDCs in service in the $9000+$ supermarkets in the UK alone. Currently RDCs in supermarkets consume about $5800 \mathrm{GWh}$ electricity annually although technical improvements (e.g. more efficient fans, lighting) mean that energy consumption per cabinet is being gradually being reduced. Developments in refrigeration systems also mean that refrigerant gas leaks and greenhouse gas emissions are also being reduced. The cabinets are typically open fronted to encourage customers to buy products although a number of retail chains have introduced cabinets with glazed doors and plastic curtains to reduce energy consumption while maintaining the optimum operating temperature of $4^{\circ} \mathrm{C}$ although these are not popular in the UK as they can discourage customer-product interaction and sales. 
On average RDCs weigh 0.5 tonnes and are made from 'common' metals (steels, aluminium alloy, copper, brass), $5+$ types of polymer, glass (fibre and plate) and medium density fibreboard; they also include lighting, electronics control systems and refrigerants. Product life depends on quality of materials used, maintenance and use and abuse in stores; life is typically 3-5 years although products are frequently replaced before necessary when stores are refurbished. RDC manufacture is traditional in that many parts are made from painted sheet metals and screwed / bolted together. Glazed panels drop into channels and shelving brackets drop in to slots so they can be easily moved by users such as sales staff. The most technically complex components are the refrigeration system, fans and the electronics, which manage these systems and control airflow and temperature. Like all electronics, the various components are soldered on to printed circuit boards (PCBs).

Current design and manufacturing methods mean that RDCs already match many of the criteria for Circular products although this is by default rather than intention: for example, $90 \%$ of the mass of cabinets derives from metals, the economic value of which encourages recycling in a wellestablished industry. Metals are also suitable for closed loop recycling because, unlike many polymers they do not downgrade when recycled; glass is also recycled easily although value is lower. Refrigerants can also be reused and recycled; in this case, reprocessing rates are high because they are subject to specialist collection and processing, which is driven by legislation. Although separation of copper in motors, fans and cables can be difficult and time consuming, relatively high value of encourages reclamation. The poorest recycling rates are for electronics because the value of individual components is so low and the infrastructure is very limited so they often end up being shredded and going to landfill.

Good quality RDCs lend themselves to product life extension because refurbishment, remanufacture, and component reuse and upgrade is relatively straightforward. This is not widely practiced however and consequently incentives in addition to appropriate design are necessary to develop this circular practice. A research study investigated the impact of Behaviour Change Interventions on the production and purchase of remanufactured RDCs. The intervention employs the Theory of Planned Behaviour (Ajzen, 1985); the graphic communication material used in the interventions was exceptionally well designed and aesthetically pleasing, which helped to engage participants. The intervention assessed the potential impact of Quality Standards (to assure retailers) and ProcessEnabling Tools (to provide guidance on the processes of purchasing and producing remanufactured RDCs) and Financial Incentives, on a stakeholder group comprised of manufacturers and retailers. The Financial Incentives - Enhanced Capital Allowance scheme - was introduced in the UK to encourage purchase and use of energy-efficient and water-saving products in industry, but the scheme only applies to new products and so changes were proposed make it available for energyefficient remanufactured products. The results of the Interventions were very positive and showed that they made a statistically significant impact on the participants' behavioural intentions towards the purchase and production of remanufactured RDCs (Muranko et al, 2018). Later research was even more positive and showed one retailer turned intention into action and placed a large order for remanufactured RDCs with a manufacturer.

\section{$<a>$ Data Centre equipment}

The final case study considers a very different and much newer sector, namely the data centre industry (DCl), which has developed very rapidly since the launch of the World Wide Web in 1989.

Such is the popularity of digital communication that by $201855 \%$ of the global population (4.2 billion individuals) were 'connected' via mobile phones and personal and commercial computing equipment and it is estimated that there are currently about 8.5 million data centres around the world (Infiniti Research, 2015). Data centres are the hidden but critical enabler of this connectivity and while some are located in cupboard-sized rooms the majority are located in stand-alone facilities, some of which are equivalent in area to $90+$ football pitches. Regardless of size they all 
house data processing, networking and storage equipment and while some centres are external service providers, others (such as those operated by banks and financial institutions) are selfservicing. The rate of growth of this industry is unprecedented and it is predicted that global capacity will increase by $500 \%$ by 2030 . It is also predicted that the sector will account for $20 \%$ of global energy use by 2025 (Andrae, 2017).

On average data centre equipment is refreshed (replaced) every 1-5 years to keep pace with developments in computing end-user services, although anecdotal evidence suggests that some large data centre operators refresh equipment every 9-12 months; either way there is a considerable volume of equipment that could be available for Circular practices. Most data centre products are comprised of metal and plastic cases that hold electrical and electronic components including a motherboard, cables, heatsinks, fans, solid state disk drives / hard drives (SSDs / HDs), ports, LEDs and buttons. The volume of equipment and mass of materials used in the sector is unknown but it is enormous. For example a typical enterprise server weighs $27 \mathrm{~kg}$ and there are 20 million in use in Europe, i.e. a total of 0.56 million tonnes embodied materials (Peiró \& Ardente, 2015). These include 'common' metals and polymers as well as 10 critical raw materials (CRM); they are identified as critical because they are essential to economic growth, but supply is at risk because of their geopolitical location, their availability in the earth's crust, (lack of) potential for substitution and current recycling rates. They are of course vital to operation of the DC industry and digital technology as a whole and any disruption to the supply chain and shortages could increase costs and ultimately destabilise economies because dependence on digital technology has become universal.

To date the data centre industry has focussed on uninterrupted operation and customer service and consequently consideration of sustainability has been very limited even though this is a young industry. There has been a drive to improve energy efficiency via changes in cooling technology for example or by locating centres near the artic, but the sustainability of hardware design is limited although external cases are designed to facilitate maintenance. The Open Compute Project is also leading standardisation and modularisation of parts to facilitate mix and match upgrades from different suppliers, which will increase system flexibility and extend overall product life. However, the majority of internal component design is based on cradle-to-grave principles because the main concern of component engineers and manufacturers is immediate functionality and performance. Furthermore, the speed and scale of DC sectoral development has far exceeded that of that of an infrastructure for reprocessing at end-of-life - which is complicated by physical factors - and reprocessing for second life - which is complicated by psychological factors.

In the case of treatment at end-of-life the easy to disassemble components such as casings are removed and either recycled, incinerate with energy recovery or sent to landfill depending where the data centre is located and who is responsible for treatment at end-of-life. Batteries may be recycled in a growing industry; however, the physical size of electronic components, the combination of materials within the components, and typical assembly and joining processes mean that current recycling processes generally involve shredding and materials separation to enable reclamation. The related mechanical and chemical processes are fairly complex and include metallurgical, heat (pyro) and/or water (hydro) processes. At present recycling facilities are very limited and processes challenging and costly, so reclamation rates are very low. This is compounded by the current low cost of many new components, which means that recycling is often uneconomical and even less attractive.

Extending product life is therefore vital to reducing Waste Electrical and Electronic Equipment (WEEE) from and the demand for CRM in the sector although there are barriers to widespread implementation. For example as in the case of RDCs, customers expect product warranties to ensure that refurbished products are 'as good as new' while the sellers of products for reuse and second life 
demand that their data is all securely and totally destroyed. This can be carried out with special over-writing software and/or by degaussing (demagnetising) HDs and SSDs. Although there is no legislation at present in the UK for example a private company - ADISA - audits and certifies data disposal services (ADISA, 2019). Nevertheless, many customers lack confidence in data wiping technology and rather than giving products a second life they demand that equipment is destroyed by shredding for recycling as described above. At present overall WEEE recycling in Europe is limited to $32 \%$ which, in conjunction with limited second life sales, means that millions of tonnes of data centre equipment, components and materials are either redundant and in storage, sent to landfill or unaccounted for (Andrews \& Whitehead, 2019).

It is apparent that data centre equipment falls into two distinct component groups and the design and manufacture of casings and other large components (such as heat sinks, fans and cables) facilitate recycling (although there is room for improvement). However, the current design and manufacturing methods of many internal components and electronics in particular are limiting recycling, reclamation and reuse of materials in closed or open loops. There is potential to develop new electronics design and manufacturing processes although inherent physics chemistry and materials properties may limit major changes in the short term. Consequently, in the sector design, manufacture and technology are currently barriers to the Circular Economy and therefore emphasis must be on the development of economic recycling and materials reclamation capabilities and on product life extension. This will increase as cultural barriers associated with data destruction for second-life products are overcome through Behaviour Change Interventions like those that were used to encourage purchase of remanufactured RDCs.

\section{$<$ a $>$ Conclusion}

The role of design as an enabler and a barrier to the development of a Circular Economy have been explored in this chapter. The history of the manufacturing and the design profession were briefly discussed in order to understand how the demand-supply-income cycle was established, evolved and grew. This was followed by analysis Linear Economy and it is evident that the role of design was crucial to the development of this economic model and to the demand-supply-income cycle. Historic circular practices, the role of design and other associated drivers were also described and it is apparent that design has previously influenced circular activity because of the various manufacturing and assembly methods employed, and the fact that products were designed for maintenance and repair, which were everyday widely practiced and taught activities. The final section presents three real world case studies that explore the role of design in conjunction with cultural and market factors in more depth in order to understand the role of design as a barrier to enabler of the Circular Economy now and in the future.

The first case study described current practice associated with the solar shading industry and product users; although the way in which products are designed enables circularity, there is room for improvement; in this case cultural and market barriers are significantly influencing behaviour. Therefore, a completely Circular Economy for the sector will only be realised through the integration of better design, cultural and market factors.

The second study focussed on refrigerated display cabinets (RDCs) and it is apparent that the design and manufacture of the products already meets many criteria for circularity; as in the case of solar shading products however this is by default rather than intent. Recycling rates for many components are already positive but rates for product life extension - and specifically the sale of remanufactured RDCs - are poor due to cultural barriers. A stakeholder study demonstrated that the barriers could be overcome through use Behaviour Change Interventions and so this in conjunction with on-going design development will help to extend circularity in the commercial refrigeration sector. 
These industries are both well established and are based on mechanical products; the final case study considers a much newer sector, the Data Centre Industry and DC equipment, which is predominantly electrical and electronic. In this case the barriers to circularity are design, cultural and market based. For example barriers to recycling at end-of-life predominantly derive from current design and manufacturing processes but they are more difficult to overcome than those in the other case studies because of the inherent properties of the materials used for electronics; technoeconomic barriers are also limiting recycling and materials reclamation at present although these could be overcome with investment in R\&D. Product life extension through refurbishment and reuse will reduce waste in the short term while recycling infrastructure is developed; however, cultural barriers such as concern about data security and destruction and product warranties are currently limiting implementation although these can also be overcome using Behaviour Change Interventions.

The case studies clearly show that industry and society in general are influenced by the legacy of linear economy. In an ever more complex and technologically challenging world, the role of design is an increasingly important as a tool for positive change. However, the Circular Economy will only be realised through thorough and complete integration of design, technology, social and economic criteria.

\section{$<$ a $>$ References}

ADISA (n.d.), Asset Disposal and Information Security Alliance, accessed 10 August 2019 at https://adisa.global/

Andrews, D. (2015), The circular economy, design thinking and education for sustainability, Local Economy, 30(3), 305-315.

Andrews, D. and B. Whitehead (2019), 'Data Centres in 2030: comparative case studies that illustrate the potential of Design for the Circular Economy as an enabler of Sustainability', paper presented at the Sustainable Innovation conference, University of the Creative Arts Centre, Epsom, 5 March

Andrews, D., Z. De Grussa, A. Chalk, D. Bush (2018), Design and the Circular Economy in the UK Blinds and Shutter Industry, in Designing for the Circular Economy, M. Charter (ed), Routledge.

Andrae, A.S.G. (2017), Total Consumer Power Consumption Forecast, paper presented the Nordic Digital Business Summit Conference, Helsinki, Finland, 5 October.

AMA (2018), Research Domestic Window Coverings Market Report: UK 2014-2018, accessed 20 July 2019 at https://www.amaresearch.co.uk/report/window-coverings-2018/.

Armengaud, E.A. and Armengaud, J. (1848), Cours élémentaire de dessin industriel à l'usage des écoles primaires, Paris: Bureau de la Publication Industrielle.

Ajzen, I. (1985), From intentions to actions: A theory of planned behaviour, in Kuhl J. and J. Beckmann (Eds.), Action control: From cognition to behavior. Berlin, Heidelber, New York: Springer-Verlag, (pp. 11-39).

Bourguignon, F. and C. Morrisson (2002), Inequality Among World Citizens: 1820-1992, American Economic Review, 92(4), 727-744.

De Grussa, Z., D.Andrews, G. Lowry, E.J. Newton, K. Yiakoumetti, A. Chalk, D. Bush (2017), 'A Case Study assessing the impact of Shading Systems combined with Night-Time Ventilation strategies on Overheating within a Residential Property' paper presented at the 38th AIVC - 6th TightVent \& 4 th venticool Conference, Ventilating healthy low-energy buildings, Nottingham, UK, 13 September.

De Grussa, Z., D.Andrews, G. Lowry, E.J. Newton, K. Yiakoumetti, D. Bush, A. Chalk (2018), 'A Realworld Study of the Relationship between Subjective Assessment of Productivity, Subjective Perception of Environmental Conditions and Objective Productivity Measures' paper presented at the, CIBSE Technical Symposium, London, UK 13 April 2018. 
Dolmans, D. (2006), Energy Saving and CO2 Reduction Potential from Solar Shading Systems and Shutters in the EU-25, accessed 20 July 2015 at: www.esso.com/images/downloads/ESCORPEU25\%20volledig.pdf.

Dresser, C. (1875), Studies in Design, reprint in 2002, Layton Utah: Gibbs Smith.

Ellen McArthur Foundation (2013) Towards a Circular Economy. Available at https://www.ellenmacarthurfoundation.org/assets/downloads/publications/Ellen-MacArthurFoundation-Towards-the-Circular-Economy-vol.1.pdf

Goossens, Y., A. Mäkipäa, P. Schepelmann, I. van de Sand, M. Kuhndt, M. Herrndorf (2007), Alternative Progress Indicators to Gross Domestic Progress (GDP) as a Means towards Sustainable Development, Brussel, Belgium: Policy Department - Economic and Scientific Policy (European Parliament).

Hutchens, M.G. (2015). High Performance Dynamic Shading Solutions for Energy Efficiency in Buildings, accessed 20 July 2015, at:

www.esso.com/images/downloads/Downloads\%20presentations/ES-SO_RT2015_HutchinsM_V6_final.pdf.

Infiniti Research (2015), High Power Consumption is Driving the Need for Greener Data Centres, accessed 14 August 2018 at http://www.technavio.com/blog/high-power-consumpton-is-drivingthe-need-for-greener-data-centers.

Kirchherr, J., L. Piscicelli, R. Bour, E. Kostense-Smit, J. Muller, A. Huibrechtse-Truijens, M. Hekkert (2018), Barriers to the Circular Economy: Evidence From the European Union (EU), Ecological Economics, 150, 264-272.

London, B, (1932), Ending the Depression through Planned Obsolescence, New York: Self Published.

McDonough W \& Braungart M (2002) Cradle to cradle: remaking the way we make things, North Point Press: New York.

Mont, O., A. Plepys, K. Whalen, J.L.K. Nußholz (2017), Business model innovation for a circular economy drivers and barriers for the Swedish industry - the voice of REES companies, Lund: Lund University.

Muranko, Z., D. Andrews, I. Chaer, E.J. Newton, P. Proudman (2019), Encouraging Remanufacturing in the Retail Refrigeration Industry, Energy Procedia, 161, 283-291

Muranko, Z., D. Andrews, I. Chaer, E.J. Newton, P. Proudman (2018), 'Developing a Circular Economy in the Retail Refrigeration Industry: The Influence of Financial Incentives, Quality Standards and Process Supporting Tools on the Behavioural Intentions to Purchase and Produce

Remanufactured Refrigeration Equipment', paper presented at the 2nd International Conference on Sustainable Energy and Resource Use in Food Chains, (ICSEF 2018), Paphos, Cyprus, 17 October.

OUP, (2010) Oxford Dictionary of English, Oxford University Press, Oxford.

Peiró, L.T. and F. Ardente (2015), Environmental Footprint and Material Efficiency Support for product policy-Analysis of material efficiency requirements of enterprise servers, accessed 4 December 2018 at http://publications.jrc.ec.europa.eu/repository/bitstream/JRC96944/lb-na27467-en-n\%20.pdf.

Stahel, W.R. (1981) Jobs for Tomorrow, New York, NY: Vantage.

Stahel, W.R., O. Giarini (1989), The Limits to Certainty, Dordrecht: Kluwer Academic Publishers.

Stevens, B. in Adamson, G. (2005), Industrial Strength Design: How Brooks Stevens Shaped Your World, Cambridge, MA: MIT Press.

Transition Engineering , accessed 10 August 2019 at https://www.transitionengineering.org/home 